\title{
História e Sobrelevação no Escrito da Diferença*
}

\author{
Marco Antonio Valentim**
}

Resumo: Esse artigo examina os conceitos de história e sobrelevação (Aufhebung) em conexão com a dialética de razão e entendimento narrada por Hegel no primeiro capítulo do Escrito da Diferença. Assim, na medida em que a sobrelevação, enquanto síntese de intuição e reflexão, constitui o âmbito fundamental da história, como formação do Espírito, a oposição harmônica entre razão e entendimento torna possível a efetivação do saber no sistema, isto é, no modo da comunidade originária de espírito e letra. Trata-se, pois, de indicar o caráter decisivo da forma - ou seja, figura - como a essência mesma do absoluto. O que aqui se procura fazer pela diferença com o sistema de filosofia de Fichte e de Schelling, que representa respectivamente as abstrações da letra sem inspiração e do espírito iletrado.

Palavras-chave: História - sobrelevação - razão - forma

... mas o pai ama, ele que vige sobre todos, muitíssimo, que seja cuidada a letra firme, e o consistente bem interpretado ...

Hölderlin, Patmos

Hegel começa a Diferença entre o sistema de filosofia de Fichte e de Schelling (1801) contestando a representação de Reinhold ${ }^{1}$ acerca da histó-

\footnotetext{
* O presente texto é o primeiro capítulo modificado de uma monografia de conclusão de curso intitulada "O Espírito e a Letra na Filosofia - Sobre o primeiro capítulo da Diferença entre o sistema de filosofia de Fichte e de Schelling, de Hegel", apresentada ao Depto. de Filosofia da UFPR em dezembro de 1999.

** Aluno da pós-graduação do Departamento de Filosofia da UFRJ.
} 
ria da filosofia. Para este, as filosofias passadas se sucederiam ao longo do tempo como formas particulares cada vez mais aperfeiçoadas de realização da tarefa filosófica, que, por sua vez, segundo Reinhold, se constituiria na investigação acerca do "fundação da realidade do conhecimento humano" (Hegel 3, p. 16). Assim, o estudo aprofundado do passado seria requisito imprescindível para que se pudesse chegar a novos avanços "tecnológicos", com o fim de dar conta, de uma vez por todas, do edifício de conhecimentos em filosofia. Hegel contraria justamente o caráter, por assim dizer, edificante dessa perspectiva historicista: a filosofia não diz respeito de modo algum a "visões peculiares <eigentümliche Ansichten>" (idem, ibidem, p. 17), a partir das quais tenham sido ou venham a ser encaradas, ao longo da história, questões filosóficas. Ou ainda, com mais ênfase, a essência da filosofia exclui tudo o que é peculiar, diverso e que se acha abstraído do princípio (Prinzip) da especulação. Se o absoluto e a razão, como sua aparição (Erscheinung), diz Hegel, são sempre iguais a si mesmos e não se caracterizam por quaisquer limitações, peculiaridades ou contingências, então a filosofia é uma só, tem uma única tarefa e chega sempre à mesma solução. Considerada do ponto de vista essencial, ela não possui história, no sentido de que, no seu âmbito, não há antecessores nem sucessores que se diferenciem pelo grau de avanço técnico alcançado por cada um: "Cada filosofia é perfeita <vollendet $>$ em si mesma e tem ... a totalidade em si" (id., ibid., p. 19). Somente do ponto de vista formal as filosofias são diferentes, e isto porque o peculiar, o limitado e o contingente pertencem justamente ao domínio da forma, mas não porque, à primeira vista, a forma pura e simplesmente tomada adquira consistência (Bestehen) filosófica. Quando, pois, um sistema defende sua peculiaridade como algo essencialmente constitutivo, é devido ao fato de que fracassa "no intento de enunciar-se na forma de uma ciência" (id., ibid., p. 17), isto se já não falhou em tornar-se especulação genuína. Em outros termos, a filosofia deve superar (überwinden) - e não diríamos aqui sobrelevar (aufheben) - todas as finitudes a que a consciência se vê acorrentada, para isso elevando-se ao absoluto e fundamentando-se "em si mesma na falta de fundamento das limitações e peculiaridades" (id., ibid., p. 19). Ao dirigir-se ao passado, ela não tomará a forma particular dos sistemas filosóficos - "mera multiplicidade de conceitos e opiniões própria ao entendimento" (id., ibid.) - como algo consistente por si, e sim unicamente como ocasião de reencontro consigo mesma e meio provisório para retornar ao absoluto. 
Mas, se é assim, se toda filosofia perde muito exprimindo-se como fato singular de uma época, de modo que o seu corpo (ou letra) acaba sempre por corromper o espírito puro que, por uma desgraça sofrida no céu das idéias, vem habitá-lo, temos então que Hegel, surpreendentemente ao contrário do que diz em obras posteriores e numa espécie de reação obscurantista à Aufklärung e às "filosofias do entendimento", faz da especulação filosófica produto exclusivo da intuição religiosa do absoluto e "possessão esotérica de alguns indivíduos singulares"? ${ }^{2}$ Ou ainda, será certo dizer que, para Hegel, em 1801 e, de modo mais preciso, na Diferença, a razão é completamente exterior à história, assim como o absoluto em relação à sua aparição? Mas, então, pensando a problemática da exposição, diríamos que a filosofia pode apenas apontar, com o dedo da alegoria ou do fragmento, para uma verdade subsistente à parte de todo dizer, que é, pois, inenunciável por princípio e que só se deixa entrever, como quiseram os românticos, na religião e na arte?

Parece-nos que tais questões devem ser respondidas negativamente, ainda que nos limitemos à Diferença, texto do período de transição do pensamento hegeliano para a Fenomenologia do Espírito. E inicialmente por duas razões, que adiantamos desde já: a presença, naquela obra, de uma interpretação figural - em projeto, pelo menos - da história da filosofia, e o emprego da noção de sobrelevação (Aufhebung) para solucionar o "impasse" entre razão e entendimento, legado pela filosofia transcendental.

Em primeiro lugar, ao mesmo tempo em que afirma de maneira categórica que, essencialmente, a filosofia nada tem de peculiar, Hegel também condena, ao propor a noção de figura (Gestalt), a parcialidade dessa perspectiva, que privilegia a essência e a intuição "mística" em detrimento da forma, a qual, por sua vez, sistemática ou não, supõe a possibilidade de enunciação, ao menos relativa, do absoluto. Além disso, é preciso reconhecer que, pela negação de toda consistência ao particular e factual, o intuicionismo romântico se mostra eminentemente a-histórico, ou então capaz apenas de uma interpretação alegórica da história, que desde logo não passam de sinais a referir um sentido inefável, exterior aos mesmos. Pois alegoria consiste aqui na "repetição informe $<$ gestaltlos $>$ do um e o mesmo, que é aplicada apenas exteriormente ao material diverso e conserva uma monótona aparência de diversidade" (idem 5, p. 21, cf. também p. 22, 26-7). A tal propósito, temos em vista a exemplaridade do modo unilateral pelo qual Novalis aparentemente concebe a relação entre o espírito e 
a letra na filosofia, que se encontra explicitado em especial no seguinte fragmento:

"A letra é apenas um auxílio da comunicação filosófica, cuja essência própria consiste no suscitamento de uma determinada marcha de pensamentos. O falante pensa produz - o ouvinte reflete - reproduz. As palavras são um meio enganoso do pré-pensar - veículo inidôneo de um estímulo determinado, específico. O genuíno mestre é um indicador de caminho. Se o aluno é de fato desejoso da verdade, é preciso apenas um aceno, para fazê-lo encontrar aquilo que procura. A exposição da filosofia consiste portanto em puros temas - em proposições iniciais - princípios. Ela é só para amigos auto-ativos da verdade. $\mathrm{O}$ desenvolvimento analítico do tema é só para preguiçosos ou inexercitados" (Novalis 11, p. 109, frag. 3).

De modo diverso, na essência do discurso, Hegel diferencia dois aspectos constituintes, o que o leva a encarar, contra as abstrações, o discurso filosófico em sua totalidade: o primeiro, por assim dizer, espiritual, surgido "desde a vivente originalidade do Espírito, o qual nela restabeleceu por si e configurou $<$ hat gestaltet $>$ auto-ativamente $<$ selbsttätig $>$ a harmonia desgarrada" (Hegel 3, p. 20), ou seja, mediante o qual é guardada a referência (Beziehung) ao absoluto; e o segundo, particular, diríamos melhor, literal por sua vez, proveniente da cisão (Entzweiung), posta pelo entendimento e dada na formação (Bildung) da época. É desse último, "o aspecto dado", na conjunção com o primeiro - livre -, que advém o sistema, a saber, a forma em que a intuição muda do absoluto se desenovela, ganhando conteúdo determinado. Portanto, afirmar que a filosofia se apresenta como figura ${ }^{3}$ significa dizer que ela dispõe de uma individualidade na qual a razão especulativa tem de configurar-se (sistematicamente), arranjando para tanto os instrumentos de uma época particular. Isto torna possível que a razão se intua a si mesma nas suas figuras históricas, de maneira simultânea, "como uma e mesma e como uma outra essência vivente" (id., ibid., p. 19); a figura é, então, o individual reportado ao absoluto, reconhecido como o que o manifesta. Mas tal ponto de vista, como veremos a seguir, não impossibilita a sua existência finita, senão mesmo a requer: se a filosofia, alerta Hegel contra o delírio (Schwärmerei) dos românticos, eleva a princípio o "aspecto negativo que afunda todo o finito no infinito ... não chega ao saber, porque 
todo saber entra, sob um aspecto, ao mesmo tempo na esfera da finitude $<$ Endlichkeit>" (id., ibid., p. 95, grifo nosso) - isto é, porque a efetividade (Wirklichkeit) própria à figura, enquanto "uma mesma e outra essência vivente", consiste precisamente na implicância mútua daqueles dois aspectos, espiritual e literal.

Desde já, isso faz com que Hegel advogue uma interpretação figural da história da filosofia, o que, por si só, parece distanciá-lo daquele intuicionismo que, à primeira vista, se anunciava, como pressuposto, na censura feita a Reinhold. Com efeito, apesar de recusar a representação reinholdiana que faz ver os sistemas do passado, em todas as suas peculiaridades e limitações, como exercícios preliminares no domínio técnico dessa "arte mecânica" em constante evolução que é a filosofia, Hegel diz explicitamente que "nós não temos permissão para abandonar a visão teleológica" (id., ibid., p. 18), apontando, pois, para a possibilidade e, até mesmo, para a necessidade de uma filosofia da história - ou ainda, uma história da filosofia. Além disso, acrescenta mais adiante que diferenciar os aspectos espiritual e literal da figura bem como perguntar pela medida na qual uma certa filosofia tem êxito em conciliá-los na produção da sua exposição (Darstellung) são procedimentos "particularmente importante $<\mathrm{s}>$ no julgamento de sistemas filosóficos" (id., ibid., p. 47), a bem dizer, quando se trata de interpretá-los historicamente. É bem possível, segundo Hegel, que uma especulação autêntica não consiga formular-se como sistema, que o "princípio filosófico" e o "princípio sistemático" não coincidam plenamente, e que a filosofia se torne dogmatismo - isto é, discurso unilateral -, ao elevar ao absoluto um termo limitado da cisão, ao invés desta mesma. Entretanto, por mais que a forma gere "ambigüidade e abuso" (id., ibid., p. 28), uma vez que condiciona necessariamente a razão conjugadora (vereinend) a figuras finitas, e o sistema não seja bem sucedido em ter purificados os enunciados que o compõem do sentido contingente em que estes são tomados pelo entendimento comum no interior da formação (cf. id., ibid., p. 33-35), isto não impede que, da perspectiva transcendental, o absoluto esteja, num tal sistema, subjetivamente construído (konstruiert), embora a identidade "não tenha sido posta, ao mesmo tempo, na aparição ou também não haja passado <übergegangen> perfeitamente à objetividade" (id., ibid., p. 50). Logo, é possível dizer que a "matéria" do materialista e o "eu" do idealista, apesar de produtos de uma reflexão inacabada, já não significam o mesmo que para o entendimento comum, pois o sentido de tais termos foi 
deslocado pela razão, quando esta eleva cada um deles ao absoluto através da aniquilação do outro na contraposição (Entgegensetzung). Assim, explica Hegel,

"a especulação verdadeira pode achar-se nas mais diversas filosofias que mutuamente se acusam de dogmatismo e de serem desvios do Espírito. A história da filosofia só tem valor e interesse quando mantém firmemente esse ponto de vista. Caso contrário, ela não dá a história de uma razão eterna e única que se expõe em formas infinitamente múltiplas, mas nada além de uma narração de ocorrências $<$ Begebenheiten $>$ contingentes do espírito humano e opiniões sem sentido que são imputadas à razão, quando o único responsável por elas é aquele que não reconhece o racional nas mesmas e, por isso, as distorce" (id., ibid., p. 47, grifo nosso).

Há, conforme Hegel, uma historiografia "ossificada" que, refugiada na indiferença e na neutralidade, elimina a novidade transformando-a em opinião morta e passado longínquo, e que, de tal modo incapaz de corresponder ao "espírito vivente" de uma filosofia, se dedica tão-só ao "aumento da coleção supérflua de múmias e ao acúmulo geral de contingências". Contra uma tal historiografia, a autêntica história da filosofia "reconhece que há verdade" (id., ibid., p. 16). Mas Hegel alerta também para o fato de que, nem por isso, a história da filosofia é levada a fazer de uma tal verdade o instrumento edificante de "grandes cabeças", supostamente empenhadas no progresso técnico de uma razão dispersa e fragmentada em concepções idiossincráticas. A história da filosofia é, segundo Hegel, justamente o devir do princípio absoluto e a configuração (Gestaltung) do mesmo em formas particulares, desde então figuras do Espírito - portanto, uma história que realiza, em meio à multiplicidade dos termos relativos e mediante o reconhecimento da especificidade destes, a teleologia da razão universal, e que, assim, é a própria dissolução (Auflösung) em ato da antinomia entre o infinito e o finito. Daí, desde a noção de figura, pode-se reencontrar tanto a historicidade das cisões discursivas, de que os sistemas filosóficos se ocupam, quanto a historicidade essencial desses sistemas em sua diversidade. Com efeito, sendo a história o movimento mesmo de desenvolvimento da razão - a objetivação do absoluto -, é necessário que a cisão, dada na formação da época, seja sobrelevada, e isto quer dizer, entre outras coisas, 
que um sistema de filosofia bem sucedido determina expectativas de ordens diversas, "científicas ou vitais", preenchendo-as; a época acolhe e assimila o sistema. Bem entendido, enquanto figura da razão, a qual se expõe livremente como história, o sistema não consiste, de todo, num simples efeito ou epifenômeno da cultura: "Quando se pode dizer de um sistema que ele fez fortuna, então uma carência universal da filosofia, que não é capaz de por si mesma parir-se como filosofia - pois, assim, ter-se-ia satisfeito com a criação de um sistema -, volta-se com uma inclinação instintiva para o mesmo" (id., ibid., p. 12-3). O mais importante a notar nisso tudo é que não há hiato entre a razão e o fato, de modo que, ao contrário de se demandar um acordo entre âmbitos radicalmente contrapostos, trata-se, antes, para além de todo desacordo empírico, de compreender a razão como fonte de sentido da facticidade, por sua vez, entendida como a necessária objetivação do absoluto. Daí Hegel fazer alusão, inclusive, à amplitude "geográfica" da contraposição entre os sistemas:

"Quando, onde e em que forma tais auto-produções $<$ Selbstproduktionen $>$ da razão como filosofias se apresentam é contingente $<$ zufällig $>$. Esta contingência precisa ser concebida a partir do fato de que o absoluto se põe como uma totalidade objetiva. É uma contingência no tempo, na medida em que a objetividade do absoluto é observada como um progredir no tempo; porém, na medida em que ela aparece como umao-lado-do-outro $<$ Nebeneinander $>$, a cisão é climática; na forma da reflexão fixada, como um mundo de essência pensante e pensada, em oposição a um mundo de efetividade, essa cisão cai para o noroeste" (id., ibid., p. 22).

A oposição entre o noroeste, a França de Descartes, e o sudeste, a Grécia de Platão e Aristóteles, corresponde, em linhas bastante gerais, ao eixo da interpretação da história da filosofia que Hegel desenvolve com respeito à transição do pensamento antigo ao moderno, de um "mundo de efetividade" a um "mundo de essência pensante e pensada", do espírito objetivo ao espírito subjetivo (cf. idem 5, p. 36-8).

É justamente esta direção, dada por uma tal concepção da história, que toma a análise hegeliana da diferença entre os sistemas de Fichte e Schelling. Dito sumariamente, no caso de Fichte, Hegel considera que a doutrina-da-ciência parte efetivamente do princípio absoluto da especula- 
ção (eu=eu), acabando, todavia, por confundi-lo com a determinação que o mesmo assume na reflexão: a consciência finita, mantida na contraposição a uma infinitude objetiva (não-eu), cuja postulação conduz à perda da referência intuitiva ao absoluto. Logo, "razão e consciência pura seriam postas como uma, elevando-se a princípio a razão compreendida <aufgefasste $>$ numa figura finita" (idem 3, p. 12), de modo que a identidade absoluta de sujeito e objeto se converteria definitivamente, para malogro da especulação, num "sujeito-objeto subjetivo". Em outros termos, Fichte permanece preso à síntese incompleta da antinomia entre eu e não-eu: na medida em que um dos termos é de ordem superior ao outro (o termo da identidade, o eu), e em que o princípio está reduzido a uma forma finita (a consciência), a síntese absoluta dos contrapostos $(\mathrm{eu}=\mathrm{eu})$, que seria preciso realizar, objetivamente, no sistema, dá lugar a uma síntese relativa, expressa por "o eu deve $<$ soll $>$ ser igual ao eu". Conclusão: "Do ponto de vista transcendental, o absoluto está construído, mas não do ponto de vista da aparição; ambos se contradizem ainda" (id., ibid., p. 50, grifo nosso) - o sistema de Fichte é, portanto, inacabado. ${ }^{4}$

Por outro lado, poder-se-ia supor que Hegel escrevera a Diferença com o propósito de explicitar o "avanço" que Schelling teria empreendido relativamente ao nível alcançado pela especulação filosófica no sistema de Fichte. Tratava-se de uma diferença, até então, apenas sentida, senão ocultada - Hegel põe em questão, a este respeito, as Contribuições de Reinhold -, a consistir em que Schelling "contrapõe ao sujeito-objeto subjetivo o sujeito-objeto objetivo na filosofia da natureza e expõe ambos unidos em algo mais elevado do que o sujeito é" (id., ibid., p. 12). Quer dizer, enquanto o mais acabado do seu tempo, o sistema schellinguiano não só configura a cisão entre sujeito e objeto, mas também a supera, reportando-a à identidade imediata de ambos. Assim, Hegel apareceria aos seus contemporâneos, antes da publicação da Fenomenologia, inevitavelmente na posição de um discípulo de Schelling, esforçando-se por situar a originalidade deste último em meio à discussão acerca da filosofia transcendental, vigente na virada do século (cf. Hyppolite 8, p. 10). Mas, tendo-se em vista a Fenomenologia, é possível notar, com nitidez, nos escritos de Jena - particularmente na Diferença e no artigo Fé e Saber (Glauben und Wissen) - o quanto de original o pensamento hegeliano já comportava com relação ao sistema de Schelling. Mais do que isso, é possível localizar na Diferença uma crítica até certo ponto velada a este último, a qual incide sobre o fato de que, com 
a "filosofia da identidade", Schelling haveria desdenhado o papel da reflexão na constituição do sistema, prendendo-se tão-somente ao aspecto negativo da aniquilação dos contrapostos, sem poder reconhecer consistência aos termos finitos no absoluto. É o que Hegel insinua ao iniciar o capítulo 3 , dedicado à "Comparação do princípio schellinguiano de filosofia com o princípio fichtiano":

"Na identidade absoluta, sujeito e objeto estão mutuamente referidos e, por isso, aniquilados; nesta medida, nada está disponível à reflexão e ao saber. Tão longe vai o fillosofar em geral que não pode chegar a um sistema; satisfaz-se com o aspecto negativo que afunda todo finito no infinito ... A este intuir da luz incolor se prende o delírio; se nele há multiplicidade é porque combate o múltiplo. Ao delírio falta a consciência sobre o que ele mesmo é, de que a sua contração está condicionada por uma expansão; ele é unilateral, pois se prende a um contraposto e faz da identidade absoluta um contraposto" (Hegel 3, p. 95).

A esse respeito, Hegel parece ter em vista o tratado, redigido more geométrico, Exposição do meu sistema de filosofia (1801) (cf. idem 4, p. 179-80, nota 22, de Hyppolite). Nesse texto, Schelling propõe a absolutidade da razão como "total indiferença de sujeito e objeto" ( $(1)$, nada sendo fora dela ( $(2)$; elege, como sua lei suprema, a identidade absoluta ( $(4)$, equivalente à forma da "identidade da identidade" $(\S 16,2)$; enfim, chega a afirmar que "entre sujeito e objeto nenhuma outra diferença, além da quantitativa, é possível" (§ 23) (Schelling 13). ${ }^{5}$ Com efeito, no "Prefácio" à Fenomenologia, Hegel refere-se àqueles que tomam por método especulativo "a dissolução do diferente e determinado e, principalmente, a sua precipitação, não desenvolvida nem justificada em si mesma, no abismo do vazio" (Hegel 5, p. 22) - quer dizer, aqueles, entre os quais parece estar Schelling, que reduzem o absoluto à identidade imediata, e que, por isso, não concedem valor positivo e necessidade às diferenças qualitativas e ao particular. Mas se, por um lado, a afirmação schellinguiana de que o princípio especulativo coincide com a identidade da identidade enquanto absoluta indiferença dá margem à crítica de Hegel, em 1807, ao pensamento que postula o absoluto como "simplicidade ou substancialidade indistinta, imóvel", objeto de uma intuição intelectual que também "recai na simplicidade inerte e expõe, de um modo não efetivo, a efetividade mesma" (id., ibid., p. 
23, grifo nosso), o mesmo, por outro lado, não parece, à primeira vista, poder ser dito com respeito à suposta crítica de Hegel a um tal intuicionismo aparentado, nas páginas da Diferença. Pois, na medida em que, nesta última, Hegel apresenta o sistema de Schelling, sugestivamente, como o mais acabado do seu tempo, parecendo com isso aprovar o que criticará pouco anos mais tarde, não caberia ver no embrião - consideravelmente desenvolvido, diga-se de passagem - o inteiro organismo de conceitos da Fenomenologia. Por conseguinte, a aproximação efetuada até aqui com a Diferença não seria irrestrita. No entanto, este escrúpulo de método vê o seu formalismo desmentido pelo fato de que as diferenças para com Schelling, nas quais a originalidade do pensamento hegeliano se deixa notar, podem ser percebidas inegavelmente em 1801 (cf. idem 4, p. 177, nota 17, de Hyppolite) - por exemplo, a propósito da valorização do papel da reflexão e da negatividade junto à construção do sistema e da conseqüente crítica ao intuicionismo, visto que este sucumbe à acusação de unilateralidade ao elevar um contraposto (no caso, a identidade pura e simples) ao estatuto de princípio absoluto. Mas o que nos interessa, aqui, não é tanto avaliar a leitura hegeliana do pensamento de Schelling em particular, mas indicar a impossibilidade de a razão intuitiva, que traz a identidade da identidade como fundamento, constituir-se numa possível via especulativa para o tratamento disso que é, para Hegel, na Diferença, a inteira questão da filosofia: a dissolução da antinomia entre a absolutidade do princípio e a finitude do dizer. Trata-se, pois, de configurar o conflito entre o saber das "luzes" e a religião estética dos românticos, através da oposição entre um entendimento apenas discursivo e uma razão meramente intuitiva, ${ }^{6}$ com vistas a determinar a singularidade do Sistema da Ciência face a ambos.

Hegel intenta, com a crítica de ambos os sistemas por meio da demarcação dos seus respectivos limites, fazer ver o movimento único de exposição da razão nessas manifestações, o qual elas, cada uma a seu modo, tendem a ocultar - seja porque, em Fichte, a forma não consegue corresponder plenamente ao princípio filosófico, ao se tomar algo condicionado (a consciência finita) como fundamento da especulação; seja porque, em Schelling, a filosofia não incorpora, para a sua efetivação, o princípio sistemático, ao se isolar o incondicionado, como pura identidade, e se o contrapor absolutamente às diferentes formas finitas em que se explicita. Mas, se o objeto da reflexão vem a ser a "pura intuição transcendental", e se, com isso, na disposição fundamental (Grundlage) da filosofia, está não 
um termo unilateral - "nem autoconsciência contraposta à matéria, nem matéria contraposta à autoconsciência" -, mas a identidade absoluta, então, o princípio sistemático, a letra, corresponde ao princípio filosófico, o espírito. Ou ainda, a reflexão torna-se especulação, já que a contraposição que estabelece passa a ser entre "uma intuição transcendental subjetiva e uma intuição transcendental objetiva, aquela eu, esta natureza - ambas sendo as mais elevadas aparições da razão intuindo-se a si mesma" (idem 3, p. 114115 , grifo nosso).

Por isso, aliás, o título da obra diz, em alemão, sistema no singular. É de propósito que Hegel se refere ao sistema, e não aos sistemas, de Fichte e de Schelling, pois só por meio do reconhecimento da inserção dos mesmos na história total da razão é que eles se tornam verdadeiramente sistemáticos. Um "sistema" justaposto extrinsecamente a outro constitui, por essa mesma razão, um fragmento isolado. Além disso, é a partir desta dupla crítica traçada na Diferença que se pode entender o diagnóstico hegeliano do "estado de necessidade" da filosofia no início do século XIX: ao "esforço acientífico das danaides, que não alcançam jamais a plenitude porque a água não cessa de derramar-se" (a reflexão infinita em Fichte) contrapõe-se a "gravidade interna do delirante, que desdenha a água" (a filosofia da identidade de Schelling): "O princípio de dispersão desdenha o supra-sensível do mesmo modo que o princípio do fanático desdenha a contraposição do supra-sensível e qualquer consistência de algo limitado junto ao supra-sensível" (id., ibid., p. 138). Antinomia esta que a Popularphilosophie de Reinhold e Bardili tenta resolver sem sucesso, já que "não compreende dentro de si ambos os pólos, senão que, numa modificação superficial e numa unificação aproximada, lhe desaparece a essência de ambos, e ela torna-se estranha para eles dois como para a filosofia" (id., ibid., p. 137) - mas a qual Hegel procura, desde logo, assimilar racionalmente mediante a consciência da identidade entre infinito e finito, ou ainda, entre a identidade mesma e a diferença: "O absoluto mesmo é a identidade da identidade e da não-identidade; contrapor e ser-um são ao mesmo tempo nele" (id., ibid., p. 96, grifo nosso). ${ }^{7}$

Contudo, caberia agora perguntar: - Como, afinal, se dá tal passagem (Übergang) de um termo a outro da cisão? Como é que se dissolvem as antinomias no absoluto? Ou ainda, de modo mais preciso, como se produz a correspondência do princípio formal ao princípio especulativo, da letra ao espírito, visto que nos encontramos, agora, face à tarefa de promover, 
sem que se caia numa contradição insuperável, a inverossímil cooperação entre o ato racional, que apreende o incondicionado, e o ato determinante do entendimento, que só pode expressá-lo condicionando-o, cindindo-o, numa palavra, julgando? Assim, chegamos àquele segundo motivo, inicialmente mencionado por nós, para rejeitarmos que, em 1801, Hegel atribuiria um privilégio exclusivo à intuição intelectual e ao espírito (entendido aqui, evidentemente, como o aspecto livre da figura, contraposto à forma, e não como o absoluto mesmo) - qual seja, a presença da sobrelevação. Com efeito, já na Diferença, Hegel lança mão da mesma a fim de tematizar o lugar no qual se passa de um momento a outro entre as contraposições históricodiscursivas que, em sua diferença, a filosofia precisa a cada vez conciliar. Diversamente da suspeita a que uma interpretação, por assim dizer, "espiritualista" pode conduzir, o emprego de tal noção não é aqui meramente negativo: sobrelevando o finito mediante a remissão do mesmo ao absoluto, a razão não o converte num puro nada, mas conserva nele, sintetizada, a série de determinações contrapostas das quais procede, e garante, com isso, conteúdo positivo, a rigor, consistência efetiva, para o termo sobrelevado. Mais precisamente, Aufhebung nomeia o ato racional que, ao elevar (erheben) o finito ao absoluto, pondo-o em referência ao mesmo, aniquila (vernichtet) seu "conteúdo" limitado imediatamente dado e pretensamente independente, a fim de que, tendo conservado sua particularidade, mas não sua peculiaridade desmedida, o finito possa efetivamente consistir como tal, o que só é possível no recolhimento (do) infinito. A Aufhebung é, por assim dizer, a absolvição do finito como forma expositiva. E de fato, Hegel escreve que "a filosofia precisa fazer justiça à separação em sujeito e objeto", tornando-a vigente tanto quanto a identidade de ambos (id., ibid., p. 96). Pois, tão logo ela se põe na "forma da existência $<$ Form der Existenz $>$ ", isto é, firma um comportamento face à aparição que não seja meramente aniquilador e então se constrói como identidade na aparição, "precisa ela pôr-se numa dualidade de forma; pois aparecer e cindir-se são um" (id., ibid., p. 106, grifo nosso). Sem isso, a especulação jamais vem a ser sistema, por permanecer numa oposição fixa entre o espírito e a letra, seja sob a aparência de uma fuga às limitações - o espirito iletrado -, seja sob a aparência da reflexão isolada - a letra sem inspiração. Porque, antes de mais nada, a natureza mais própria da razão é conjugar, a priori e sistematicamente, a essência espiritual e a forma literal, quer dizer, ser desde logo "um com o seu ato", como "puro expor-se de si mesma" (Hegel 3, p. 46). E as- 
sim, reafirma-se antecipadamente o caráter absoluto da forma, tal como referido no "Prefácio" à Fenomenologia:

"É justamente porque a forma é tão essencial à essência quanto esta o é a si mesma que a essência não é apreensível e exprimível simplesmente como essência, isto é, como substância imediata, ou como pura intuição de si do divino, mas também como forma, e na riqueza integral da forma desenvolvida; unicamente assim a essência é apreendida e exprimida em sua efetividade" (idem 5, p. 24).

Ademais, a Aufhebung possui especial relevância por designar numa palavra a atividade do "saber transcendental" (idem 3, p. 42) - síntese sistemática de intuição e reflexão. Portanto, não se trata nem de uma operação simplesmente negativa (como quereria o misticismo criticado por Hegel), nem de uma operação eminentemente positiva (como propugnam as doutrinas, igualmente objeto da crítica hegeliana, que almejam a edificação da filosofia num "sistema" enquanto corpo de conhecimentos definitivo). Para fugir tanto à ênfase exagerada sobre o aspecto positivo, que as traduções "superação" e "suprassunção" sugerem, quanto à pretensa exclusividade do aspecto negativo, proposta na tradução "supressão", escolhemos verter, nas maioria das ocorrências, o termo alemão para "sobrelevação", tradução na medida do possível literal, que só tem validade se relevarmos o sentido que a Aufhebung assume na Diferença. No entanto, como Hegel não emprega o termo sempre univocamente, traduzimo-lo por "supressão" ou "superação" nos trechos em que a Aufhebung designa, ao contrário da maioria das vezes, apenas o momento unilateral em que a razão nega, subjetivamente, o entendimento (cf. id., ibid., p. 21-24, 28). ${ }^{8}$ É quando o entendimento abstrato, ao constatar que a proposição que tomava por fundamento absoluto corresponde, na realidade, a uma antinomia formalmente insuperável, sucumbe ao que a "Introdução" da Fenomenologia denominará ceticismo: "Ela <esta figura da consciência> é precisamente o ceticismo, o qual vê no resultado apenas sempre o puro nada e abstrai de que este nada é determinadamente o nada daquilo de que ele resulta" (idem 5, p. 74). Na verdade, como "negação determinada", a sobrelevação constitui a negação em que se faz "a passagem $<$ Übergang $>$ através da qual o progresso pela série completa das figuras < do Espírito $>$ resulta de si mesma" (id., ibid., p. 74), passagem que, compreendida do ponto de vista do saber absoluto, demonstra 
tão-somente a pura nascividade da experiência, mas não a existência em si determinada de um objeto mais pleno. O que não significa, porém, que o absoluto coincide com uma espécie de "ponto-de-indiferença" em que "tudo é igual" - "a noite em que todas as vacas são negras", dirá o "Prefácio" em alusão a Schelling (id., ibid., p. 22). Pois, na sobrelevação, as fixações firmadas pela atividade isolante do entendimento discursivo desaparecem unicamente para dar lugar às "oposições viventes" (Heidegger 7, p. 392, grifo nosso) fundadas sistematicamente no movimento de absolvição do princípio:

"A reflexão isolada, como pôr de contrapostos, seria um sobrelevar do absoluto <ein Aufheben des Absoluten>; ela é a capacidade do ser e da limitação. Mas a reflexão tem, como razão, referência ao absoluto e só é razão por meio desta referência; a reflexão se aniquila, desde logo, a si mesma e todo ser e limitado, enquanto ela o refere ao absoluto. Ao mesmo tempo, porém, justamente por sua referência ao absoluto, o limitado tem uma consistência" (Hegel 3, p. 26, grifo nosso).

Por isso, quando Hegel nomeia Aufhebung o movimento que, sob o aspecto negativo, aniquila a cisão entre os termos adversários, este não deve ser entendido no sentido de uma unificação contrária a toda diferença, mas como conjugação - Vereinigung - entre opostos no âmbito de um fundamento uno que, escapando às oposições, promove tal articulação. Como oposição harmônica, a conjugação é, sim, o contrário da diversidade (Verschiedenheit), que propriamente caracteriza a inconsistência do que está cindido e, assim, somente justaposto a outro: "A diversidade é, antes, o limite da coisa; ela está aí onde a coisa cessa, ou é o que a coisa não é" (idem 5 , p. 13). Num seminário que toma por tema precisamente a Diferença, Heidegger enfatiza que não se pode, a rigor, compreender esta conjugação como unificação (Heidegger 7, p. 375-6), que é, porém, o termo mais usado para se traduzir Vereinigung. Uma tal compreensão, que por sinal é criticada por Heidegger, acha-se na base de toda interpretação metafísica do pensamento de Hegel, na medida em que nela está suposto que, com a sobrelevação, se progride positivamente em direção à mais abrangente unificação, que exclui todo múltiplo, feita inadvertidamente equivalente ao absoluto. 
Ora, antes de apressadamente entendermos a proposição desse princípio de conjugação como ocasião de um "deslize" ou recaída dogmática em relação à via crítica aberta por Kant, é preciso atentar para o fato de que a síntese de intuição e reflexão, da qual depende a possibilidade de toda apresentação, decorre da mesma necessidade que manda distingui-los, razão e entendimento, entre si, para livrar a especulação do dogmatismo, quer dizer, decorre da necessidade mesma que impele a expor a diferença entre o incondicionado e o condicionado, a qual, por não equivaler a uma mera distinção mas à condição fundamental de possibilidade para toda distinção, corresponde à identidade absoluta de ambos, intuída no saber transcendental. Com isso, parece que Hegel leva a cabo o que Kant mesmo afirma a respeito dessa relação: que "o mundo inteligível contém o fundamento do mundo sensível, e portanto também das suas leis" (Kant 10, p. 249), ou então, que "o caráter inteligível é a causa transcendental do caráter empírico" (Kant 9, p. 277, B574) $)^{9}$ - em suma, que o entendimento é uma operacionalidade da razão. Dessa perspectiva, a diferença, agora entre a Crítica e o Sistema da Ciência, deve-se mais fundamentalmente ao "instrumental de construção da época particular" (Hegel 3, p. 19), que resulta diverso entre os casos: enquanto a Crítica volta-se contra o abuso da razão que extrapola os limites da experiência com vistas ao conhecimento teórico do supra-sensível, sob o risco de anular o seu uso puro, isto é, contra o dogmatismo da metafísica, o Sistema da Ciência, por sua vez, contrapõe-se à deturpação da Crítica, operada pelos epígonos, numa espécie de teoria do conhecimento que postula uma cisão insuperável - a qual sempre se tenta, das mais diversas maneiras, superar - entre o absoluto e o conhecimento. Dito de outro modo, com a Aufhebung, busca-se redimir a Übergang de se haver pervertido em passagem entre domínios isolados, contrapostos realmente, a favor da exposição do absoluto como o "entre" fundamental - a passagem propriamente dita. E é como inverossímil não-passagem que provêm a letra sem inspiração e o espírito iletrado: os insucessos de um único esforço errante (passante) de exposição que a pensa para si abstratamente, isto é, a partir de termos objetivamente dados (uma coisa incondicionada e uma coisa condicionada).

Logo, bem entendido, não deve soar como contra-senso que "justamente por sua referência ao absoluto, o limitado tem uma consistência". Para tanto, é essencial ter visto que, concomitante à negatividade da reflexão, "o saber tem um lado positivo: a intuição" (id., ibid., p. 42), a oferecerse unicamente a partir da impossibilidade de uma separação e singularização 
absolutas, resultantes do trabalho de uma reflexão largada a si mesma. Assim, abdicar da "intuição transcendental" implicaria "dispersar-se ... numa série sem fim $<$ endlos $>$ de finitudes", visto que o pressuposto fundamental é então uma contraposição absoluta entre ser e conceito, e a passagem entre ambos se torna com isso um "salto injustificado" (id., ibid., p. 43). Para que o incondicionado não seja tomado como algo meramente formal, "na forma de uma idéia contraposta ao ser", isto é, na forma do mau infinito, ou ainda, para que a passagem entre ser e conceito seja efetiva, verdadeiramente infinita, como origem para determinação, torna-se preciso elevar à consciência a identidade absoluta, isto é, orientar sistematicamente o entendimento à razão. E se a especulação tem por propósito mais próprio "saber se e como, diz Heidegger, o movimento dialético ele mesmo pode evitar recair sob a dominação do finito, sob a forma da falsa infinitude, da End-losigkeit" (Heidegger 7, p. 404), o sistema não deve optar entre o incondicionado como causa primeira e a série sem fim de condições, por assim dizer, entre dogmatismo e empirismo, mas tão-só fazer consistir, de modo propriamente finito, os objetos da reflexão, referindo-os ao movimento dialético graças ao qual, a cada vez, se produz a diferença entre as múltiplas identidades relativas e a identidade absoluta una. A possibilidade de todo finito vir a ser enquanto tal depende, portanto, da impossibilidade de o absoluto se propor definitivamente como um algo que apenas poderia se determinar em referência à diferença mesma como esse movimento com que o absoluto coincide originariamente, enquanto pura passagem.

Por isso, a fim de que não se confunda o saber transcendental com a intuição de uma inefetiva indiferença entre termos contrapostos, mas que se o compreenda como a essência mesma do que, a rigor, Hegel chama história - a saber, o devir da diferença ou a objetivação do absoluto -, vale aqui chamar atenção para o fato de que as noções de negatividade discursiva e positividade intuitiva são, por assim dizer, reversíveis. O entendimento determina: com isso, a reflexão tem um lado positivo. Mas, da perspectiva racional, e uma vez que o entendimento contrapõe forçosamente ao simplesmente pôr, toda determinação é negação; pois a antinomia demonstra a negatividade da reflexão. Já a intuição tem, do ponto de vista do entendimento, um lado negativo: ela aniquila os termos contrapostos (a cisão). No entanto, é igualmente positiva, já que, ao referi-los ao absoluto, opera a síntese dos contrapostos numa identidade mais elevada. Por sua vez, esta é ainda relativa, tomando parte, a seguir, numa nova contraposição. E, assim, 
toda negação é negação determinada. ${ }^{10}$ Contudo, para que uma tal negatividade, não vazia, se torne possível, a razão especulativa deve conjugá-las, reflexão e intuição, e isso se faz, como vimos, no âmbito da sobrelevação ele, sim, unicamente absoluto -, sem o que ou bem a razão estaciona na antinomia do entendimento, destruindo-se por não estar apta a dissolvê-la, ou bem não sai do lugar, permanecendo na imóvel e indiferente coincidência consigo mesma, e nesse caso o absoluto acaba confundido com uma identidade estática.

Só que Hegel não é cético nem tampouco eleata - tais destinos ele mesmo reserva aos esclarecidos e aos iluminados, respectivamente. É o que podemos concluir a partir da dialética entre razão e entendimento, narrada por Hegel ao longo do primeiro capítulo da Diferença (cf. id., ibid., p. 2030). Em linhas gerais, vimos que o entendimento não conduz, por si só, ao saber, pois, na falta da intuição absoluta, é incapaz de realizar a exposição do princípio especulativo - não passa da literalidade vazia de sentido, permanecendo entendimento raciocinante (räsonierender Verstand). Além disso, sugerimos também que, de modo similar, a intuição informulada, apreensão imediata do absoluto, não dá conta, sozinha, de construir o sistema, mas requer para tanto a mediação da reflexão. Assim, a razão intuitiva, separada da forma de exposição, conserva uma unilateralidade parelha à da reflexão isolada, a unilateralidade da alegoria. E de fato, este era o sentido da análise das noções hegelianas de história e sobrelevação: a demonstração da unidade (não-indiferença) e da implicância mútua (oposição harmônica) de razão e entendimento na produção do absoluto para a consciência. Pois, para Hegel, o saber é a razão que chega a si, restaurando o caráter genético de todo fático, na completude do seu agir, ou seja, tanto "força do pôr da totalidade contraposta objetiva e subjetiva" quanto "força do absoluto negativo" (id., ibid., p. 26). Enfim, como unidade de reflexão e intuição, a razão absoluta corresponde precisamente à definição de figura, porque assim manifesta "o todo na singularidade de uma determinação" (idem 5, p. 33): "A reflexão como capacidade do finito e o infinito contraposto a ela estão sintetizados na razão, cuja infinitude o finito apreende em si" (idem 3, p. 28, grifo nosso). ${ }^{11} \mathrm{Com}$ isso, terminamos por fornecer algumas indicações para a comprovação de que o propósito de Hegel, no Escrito da Diferença, consiste, desde logo, em reconciliar a Aufklärung e a idéia especulativa na figura sintética de uma discursividade intuitiva ou de uma intuição discursiva: isto é, o sistema. Eis o que diz o "Primeiro Prefácio" à 
Ciência da Lógica na passagem a que, desde logo, se orienta a nossa interpretação:

"O entendimento determina e mantém firmes as determinações; a razão é negativa e dialética, porque dissolve as determinações do entendimento em nada; é positiva, porque produz o universal, e nele compreende o particular. Assim como o entendimento pode ser considerado algo separado da razão em geral, assim também a razão dialética pode ser entendida como algo separado da razão positiva. Mas, em sua verdade, a razão é Espírito, que é mais elevado que ambos, como razão intelectiva $<$ verständige Vernunft $>$ ou entendimento racional <vernünftiger Verstand>" (idem 6, p. 16-17).

Abstract: This article examines the concepts of history and overcoming (Aufhebung) conecting them to the dialects of reason and understanding narrated by Hegel along the first chapter of the Diference's Writing. So, as well as the overcoming as synthesis of intuition and reflection constitutes the fundamental ambit of history as formation of the Spirit, the harmonic oposition between reason and understandig makes possible the efectiveness of knowledge in the system, i. e., in the originary community of spirit and letter. Therefore, the task is to indicate the decisive character of the form - that is, figure - as the very essence of the absolute, which we here attempt to do by means of the diference to the Fichte's and Schelling's system of philosophy, what represents, respectively, the following abstractions: the letter without spirit and the ilitterated spirit.

Key-words: History - overcomig - reason - form 


\title{
Notas
}

\begin{abstract}
${ }^{1}$ Hegel refere-se ao "Primeiro Caderno" das Contribuições a uma visão de conjunto mais clara do estado da filosofia no início do século XIX, de Reinhold, também de 1801.

2 “.... possessão esotérica, pois nesse caso ela $<$ a ciência $>$ está presente apenas em seu conceito ou interioridade; de alguns indivíduos singulares, pois a sua aparição sem expansão singulariza a sua presença" (Hegel 5, p. 20).

${ }^{3}$ Para ilustrar a diferença entre o intuicionismo criticado por Hegel e a identidade, que preconiza, entre intuição e reflexão, utilizamos a distinção que é feita por Auerbach entre alegoria e figura no ensaio "Figura" - não de modo arbitrário, é bom destacar, já que o próprio autor confirma a presença da interpretação figural em Hegel e diz ter servido-se dela em tal forma (Auerbach 1, p. 60). Para Auerbach, a figura se define por relação ao preenchimento (Erfüllung), que é a sua verdade. Porém, ainda como "sombra" ou "imagem" de algo diferente de si mesma, não perde consistência histórica - a figura é, antes de mais nada, uma realidade singular. Da mesma forma, a sua verdade também corresponde a um evento da história, dando-se tão concretamente quanto a própria figura. Trata-se, por exemplo, da relação entre Moisés e Cristo, conforme a exegese de Paulo, o qual inaugura, segundo Auerbach, a interpretação figural da história (id., ibid., p. 31). Em outra passagem, o autor diferencia figura e littera: ambas dizem respeito ao sentido literal dos acontecimentos, mas aquela conserva uma alusão velada ao preenchimento; a figura é, pois, "o termo do meio entre littera-historia e veritas" (id., ibid., p. 41). Já a diferença entre figura e alegoria consiste, sobretudo, no fato de que o signo figural é essencialmente concreto, enquanto que a alegoria quase sempre se refere a abstrações que não comportam sentido histórico - por exemplo, virtudes e elementos de doutrinas "filosóficas" e místicas (id., ibid., p. 46-7).

${ }^{4}$ Para o desenvolvimento inteiro da crítica a Fichte, cf. capítulo 2 da Diferença, intitulado "Exposição do sistema fichtiano" (Hegel 3, p. 52-93).
\end{abstract}

${ }^{5}$ Comentando a Darstellung para indicar que as alusões de Hegel à reação contra o sistema de Fichte - na qual o princípio de identidade fora hipostasiado no combate à "atividade separadora da reflexão" (Hegel 3, p. 94-96, 136-138) - se dirigem, de fato, a Schelling, Rodríguez Tous escreve: "Schelling fala de despotenciação do absoluto para explicar a passagem do absolutamente incondicionado ao condicionado, do infinito ao finito. ... As observações de Fichte $<$ ao seu exemplar da Darstellung> são assombrosamente parecidas às que Hegel fizera desde as 
páginas da Diferença: Schelling partiu de um ponto-de-indiferença que não é senão uma definição inicial. A única conclusão que se pode derivar dos primeiros parágrafos é a imobilidade auto-idêntica do princípio de identidade absoluto. Tudo parece dar igual. Fichte o tacha de arbitrário, contraditório, sofista e spinozista" (Rodríguez Tous 12, p. XXXV).

6 "Esta oposição parece constituir o nó principal que a formação científica de nosso tempo trabalha em desfazer e sobre que ela ainda não se entende convenientemente. Uma parte se vale da riqueza de materiais e da inteligibilidade, a outra despreza, para não dizer mais, esta inteligibilidade e se vale da racionalidade imediata e da divindade" (Hegel 5, p. 20).

${ }^{7}$ Com apoio nessas considerações, poder-se-ia até mesmo sugerir que a interpretação que Hegel fornece acerca da relação entre o Sistema da Ciência e o idealismo alemão, nas Lições sobre a História da Filosofia, é esboçada nas páginas da Diferença, interpretação esta que, segundo a sua forma acabada, Hyppolite assim resume: "Fichte representaria o idealismo subjetivo, a eterna oposição do eu e do não-eu, uma oposição não resolvida, mas que deve unicamente resolver-se, uma filosofia da ação moral; Schelling, o idealismo objetivo, a identidade no absoluto do eu e do não-eu, uma filosofia da contemplação estética; Hegel, o idealismo absoluto, conservando no próprio seio do absoluto a dialética da reflexão característica de Fichte, uma filosofia da síntese concreta" (Hyppolite 8, p. 11, grifo nosso).

${ }^{8}$ O primeiro capítulo da Diferença acha-se traduzido nos Cadernos PET-Filosofia 2: Filosofia Analítica - Filosofia e Literatura (Curitiba: Departamento de Filosofia da UFPR, 1999, p. 125-75).

${ }^{9}$ Trata-se do trecho da solução da terceira antinomia da razão pura intitulado: "Elucidação da idéia cosmológica de uma liberdade em ligação com a necessidade universal da natureza" (B570-586).

${ }^{10}$ A passagem aqui comentada é a seguinte: "Enquanto a especulação é encarada do lado da mera reflexão, a identidade absoluta aparece em sínteses de contrapostos, logo, em antinomias. As identidades relativas, nas quais a [identidade] absoluta se diferencia, são verdadeiramente limitadas e, nessa medida, são para o entendimento, e não antinômicas; ao mesmo tempo, porém, porque são identidades, não são puros conceitos do entendimento; e elas precisam ser identidades, pois, numa filosofia, nada que é posto pode ficar sem referência ao absoluto. No entanto, do lado desta referência, todo limitado é mesmo uma identidade (relativa) e, enquanto tal, para a reflexão, algo antinômico - e esse é o aspecto negativo do saber, o formal, que, regido pela razão, destrói-se a si mesmo. Além desse aspecto 
negativo, o saber tem um positivo, precisamente a intuição" (Hegel 3, p. 41-2; grifo nosso).

11 “... não somente a substância do indivíduo, mas o Espírito do mundo mesmo teve a paciência de percorrer essas formas em toda a extensão do tempo, e de empreender o prodigioso labor da história universal, na qual ele configurou $<$ herausgestaltete $>$ em cada forma, na medida em que ela o comportava, o conteúdo total de si mesmo" (Hegel 5, p. 33-4).

\section{Referências Bibliográficas}

1. AUERBACH, E. Figura, trad. Duda Machado. São Paulo: Ática, 1997.

2. HEGEL, G. W. F. Diferencia entre el sistema de filosofia de Fichte y el de Schelling, trad. Juan Antonio Rodríguez Tous. Madrid: Alianza Editorial, 1989.

3. _ . "Differenz des Fichteschen und Schellingschen Systems der Philosophie", in: Werke [in 20 Bänden]: 2. Jenaer Schriften: 1801-1807, 7-138. 2. Aufl., Frankfurt-am-Main: Suhrkamp, 1990.

4. . Préface de la Phénoménologie de l'Esprit (Vorrede zur Phänomenologie des Geistes), trad. J. Hyppolite. Paris: AubierMontaigne, 1966.

5. _. Werke [in 20 Bänden]: 3. Phänomenologie des Geistes. 3. Aufl., Frankfurt-am-Main: Suhrkamp, 1991.

6. _. Werke [in 20 Bänden]: 5. Wissenschaft der Logik I. 2. Aufl., Frankfurt-am-Main: Suhrkamp, 1990.

7. HEIDEGGER, M. “Séminaire du Thor: 1968”, in: Questions III et IV, 372-414. Paris: Gallimard, 1976. 
8. HYPPOLITE, J. Introdução à filosofia da história de Hegel, trad. José Marcos Lima. Rio de Janeiro: Elfos, 1997.

9. KANT, I. Crítica da Razão Pura, trad. Valerio Rohden e Udo Baldur Moosburger. $2^{a}$ ed., São Paulo: Abril Cultural, Os Pensadores, 1983.

10. Fundamentação da Metafísica dos Costumes, trad. Paulo Quintela. São Paulo: Abril Cultural, Os Pensadores, 1974.

11. NOVALIS. Pólen-Fragmentos, Diálogos, Monólogo, trad. Rubens Rodrigues Torres Filho. São Paulo: Iluminuras, 1988.

12. RODRÍGUEZ TOUS, J. A. "Introducción", in: Diferencia entre el sistema de filosofia de Fichte y el de Schelling, IX-XLVII. Madrid: Alianza Editorial, 1989.

13. SCHELLING, F. "Darstellung meines Systems der Philosophie", in: Werke, Dritter Hauptband: Schriften zur Identitätsphilosophie, 1801-1806, 1-108. 3. Aufl., München: Beck, 1977. 